\title{
The Prevalence of Shoulder Pain and Its Functional Limitations Among Patients With Uncontrolled Diabetes
}

Abdulrahman Aljethaily ${ }^{1}$, Abdulrahman Alshuwayrikh ${ }^{1}$, Saleh Alkhonezan ${ }^{1}$, Abdullah Alasmari ${ }^{1}$, Mohammed Almakdob ${ }^{1}$, Amjad Albogami ${ }^{1}$, Abdulmalik Aloriney ${ }^{2}$, Ibrahim Ahmed ${ }^{2}$, Bader Alzahrani ${ }^{3}$

1. Medicine, College of Medicine, Imam Mouhammad Ibn Saud Islamic University, Riyadh, SAU 2. Family Medicine, College of Medicine, Imam Mouhammad Ibn Saud Islamic University, Riyadh, SAU 3. Family Medicine, Security Forces Hospital, Riyadh, SAU

Corresponding author: Saleh Alkhonezan, saleh.m.alkhonezan@gmail.com

\section{Abstract \\ Objectives}

To investigate the prevalence of shoulder pain and its functional limitations among patients with uncontrolled diabetes mellitus (DM).

\section{Methods}

This is a cross-sectional study that was conducted over a period of four months from October 2019 to January 2020 and included all patients with uncontrolled DM (HbA1c > 9) who are visiting the diabetes clinic at Security Forces Hospital during the study period. Telephone interviews were held by a physician from the Family Medicine Department using a previously validated questionnaire, that is, the American Shoulder and Elbow Surgeons Evaluation Form.

\section{Results}

A total of 285 patients were included in the study; 156 (54.7\%) were females and 129 (45.3\%) were males. Most (51.1\%) of the patients aged $45-64$ years. The majority of the patients $58.9 \%$ had type II DM and $41.1 \%$ of them had type I DM. The mean HbA1c level was 10.56. Of the patients are having shoulder pain (109; $38.2 \%), 42.5 \%$ were between 45 and 64 years of age and $44.1 \%$ were between 65 and 96 of years. While 176 (61.8\%) of the participants had no pain at all, $70.5 \%$ males and $54.5 \%$ females did not have shoulder pain $(\mathrm{p}<0.001)$. The mean shoulder pain intensity for all patients was $5.81(\mathrm{SD}=3.21)$, ranging from $4.71(\mathrm{SD}=3.15)$ to 6.13 ( $\mathrm{SD}=3.29)$, according to different age groups, and showed a significant correlation $(\mathrm{p}<0.05)$.

\section{Conclusions}

Increasing prevalence of shoulder dysfunction is making physicians alert regarding early diagnosis and management of the disease. Thus, it should be mandatory to include screening, prevention, and

Review began 10/16/2020 Review ended 11/02/2020 Published 11/15/2020

\section{() Copyright 2020}

Aljethaily et al. This is an open access article distributed under the terms of the Creative Commons Attribution License CC-BY 4.0., which permits unrestricted use, distribution, and reproduction in any medium, provided the original author and source are credited. rehabilitation strategies for shoulder dysfunction in diabetic care programs to improve the daily lifestyle of the patients.

Categories: Endocrinology/Diabetes/Metabolism, Family/General Practice, Orthopedics Keywords: diabetes, shoulder pain, ases

\section{Introduction}

Diabetes mellitus (DM) is a chronic disease that has turned into a major risk to human health in recent years. It possesses a variety of complications such as nephropathy, retinopathy, heart disease, and stroke. Musculoskeletal disease is also one of the important symptoms observed in diabetic patients, which presents as Dupuytren's contracture, stiff hand syndrome, tendinitis, adhesive capsulitis (frozen shoulder), and periarthritis of the shoulder [1-2]. Among all these, shoulder pain is found to be the most common symptom, which is characterized by pain and restricted movement [3]. Shoulder pain can lead to hindrance in daily activities that can directly or indirectly influence the metabolic processes of our body, thus affecting the quality of life [4].

The prevalence of DM was observed to be around 151 to 171 million in the year 2000, and it is estimated that it will be three times by the year 2050 [5]. A study by Alqurashi et al [6] in 2011 on the population of Saudi Arabia revealed that the prevalence rate of diabetic patients was approximately $30 \%$, with the involvement of $34.1 \%$ males and $27.6 \%$ females. Various studies reported that shoulder disorders are found to be more prevalent (27.5\%) in diabetic patients than in patients suffering from general medical conditions (5\%) [6-7]. The most common shoulder disorders observed in patients are frozen shoulder, also known as "adhesive capsulitis" and rotator cuff disease [6]. 
It has been observed that the underlying pathophysiological processes of shoulder pain involve capsular inflammation following fibrosis. This manifestation is modulated by various mediators such as growth factors, enzymes, inflammatory cytokines, and matrix metalloproteinases (MMPs) [8-9].

The function of the upper limb is primarily dependent on the shoulder joint. Past studies have shown a direct link between the duration of DM-associated shoulder pain and control of blood sugar levels. Studies have also observed the role of social, genetic, and environmental factors in this ailment [10-11]. Since years, shoulder involvement in diabetic patients is not very well understood [12]. In the population of Saudi Arabia, we observed that only a few studies [13-14] have been conducted that reveal the prevalence of chronic pain due to various musculoskeletal disorders in diabetic patients, but there was no study that observes the relationship of $\mathrm{HbA1c}$ with shoulder pain and the prevalence of shoulder pain in patients suffering from DM.

Thus, this study was conducted with the aim to determine the prevalence of shoulder pain and its functional limitations among patients with uncontrolled DM at Security Forces Hospital using the American Shoulder and Elbow Surgeons (ASES) Evaluation Form.

\section{Materials And Methods}

This is a quantitative cross-sectional study conducted over a period of four months from October 2019 to January 2020. We enrolled all patients with uncontrolled DM (HbA1c > 9) who visited the diabetes clinic at Security Forces Hospital over the study period by registering their telephone numbers. Also, we excluded all patients who had known to have psychiatric illness and thus incapable of answering questions, had gestational DM, were medically unstable, or were unwilling to participate. Then, telephone interviews were held by a physician from the Family Medicine Department using the ASES Evaluation Form.

The ASES Evaluation Form is developed by the Committee of American Shoulder and Elbow Surgeons to facilitate the assessment of shoulder problems. It is a scoring tool for shoulder pain and its functional limitations; 100 points are the maximum score, and half of the score (50\%) is driven from the shoulder pain and its intensity and the other half is a cumulative score driven by 10 questions about daily activity. Each question can be scored as an ordinal scale (from 0 to 3 points). As the ASES scores higher, it correlates with better function and less pain.

The data were entered into a Microsoft Excel spreadsheet and analyzed using Statistical Package for the Social Sciences (SPSS) (IBM Corp., Armonk, NY, USA). All categorical variables, which include gender, marital status, smoking status, and educational level, were summarized and reported as frequency and percentage. Continuos variables were summarized as mean and standard deviation. p-Values of $<0.05$ were considered statistically significant.

This study was approved by the Ethics Committee of the Security Forces Hospital. Verbal consent was obtained from all participants, after having a brief explanation about the aims of the study and the contents of this telephone interview. The identity of the patients as well as the raw data, which include personal information, were kept confidential.

\section{Results}

A total of 285 patients were included in the study. Most (51.1\%) of the patients aged $45-64$ years, whereas only $7 \%$ were younger than 18 years old. Of the patients, 156 (54.7\%) were females and 129 (45.3\%) were males, most (67.4\%) of them were married, $16.5 \%$ were single, and only $1.8 \%$ were divorced. Most of the patients had a low level of education (79.3\%), either secondary education or less. Also, $43.9 \%$ were unemployed, $9.8 \%$ were housewives, and only $3.2 \%$ were working in the private sector. Overall, $77.9 \%$ of the patients were never smokers and $12.3 \%$ were currently smoking. Type II D was prevalent in $58.9 \%$ and type I DM in 41.1\%; the mean HbA1c level was 10.56 . The duration of DM was more than 10 years in $82.1 \%$ of them, and $71.9 \%$ were on insulin injection treatment. Of the 285 patients, 109 (38.2\%) had shoulder pain and the rest 176 (61.8\%) had no pain at all. Concerning shoulder pain, 56.9\% of patients between 45 and 64 years of age and $23.9 \%$ between 65 and 96 years stated that they have shoulder pain $(p>0.05)$. Among males and females, $34.9 \%$ and $65.1 \%$, respectively, had shoulder pain $(\mathrm{p}<0.001)$. Mostly, patients having more than secondary education did not have shoulder pain ( $p>0.05)$. The majority $(75.2 \%)$ of participants who had shoulder pain never smoked ( $\mathrm{p}<0.05)$. Of those having shoulder pain, the vast majority $(61.5 \%)$ have type II DM, whereas $38.5 \%$ had type I DM. The participants who exercised regularly represented the majority (59.6\%) of patients with shoulder pain (Table 1).

\begin{tabular}{|c|c|c|c|c|}
\hline ractor & $\begin{array}{l}\text { All patients, } n=285 \\
(100 \%)\end{array}$ & $\begin{array}{l}\text { Participants having shoulder pain, } n= \\
109(38.2 \%)\end{array}$ & $\begin{array}{l}\text { Participants not having shoulder pain, } n= \\
176(61.8 \%)\end{array}$ & $\begin{array}{l}\text { p- } \\
\text { Value }\end{array}$ \\
\hline \multicolumn{5}{|l|}{ Gender } \\
\hline Male & $129(45.3 \%)$ & 38 (34.9\%) & $91(51.7 \%)$ & \\
\hline
\end{tabular}




\section{Cureus}

\begin{tabular}{|c|c|c|c|c|}
\hline Female & 156 (54.7\%) & $71(65.1 \%)$ & 85 (48.3\%) & \\
\hline \multicolumn{5}{|l|}{ Age, years } \\
\hline $0-17$ & $20(7.0 \%)$ & $7(6.4 \%)$ & $13(7.4 \%)$ & \multirow{4}{*}{0.053} \\
\hline $18-44$ & $60(21.1 \%)$ & $14(12.8 \%)$ & $46(26.1 \%)$ & \\
\hline $45-64$ & 146 (51.2\%) & 62 (56.9\%) & $84(47.7 \%)$ & \\
\hline 65-96 & $59(20.7 \%)$ & $26(23.9 \%)$ & $33(18.8 \%)$ & \\
\hline \multicolumn{5}{|l|}{ Occupation } \\
\hline Unemployed & 125 (43.9\%) & $66(60.6 \%)$ & 59 (33.5\%) & \multirow{7}{*}{0.000} \\
\hline House wife & 28 (9.8\%) & $9(8.3 \%)$ & 19 (10.8\%) & \\
\hline Retired & $27(9.5 \%)$ & $6(5.5 \%)$ & $21(11.9 \%)$ & \\
\hline Student & $24(8.4 \%)$ & $3(2.8 \%)$ & $21(11.9 \%)$ & \\
\hline Civil servant & $26(9.1 \%)$ & $11(10.1 \%)$ & $15(8.5 \%)$ & \\
\hline $\begin{array}{l}\text { Private sector } \\
\text { employee }\end{array}$ & $9(3.2 \%)$ & $0(0.0 \%)$ & $9(5.1 \%)$ & \\
\hline Military personnel & 46 (16.1\%) & $66(12.8 \%)$ & $32(18.2 \%)$ & \\
\hline \multicolumn{5}{|l|}{ Educational status } \\
\hline $\begin{array}{l}\text { Secondary education } \\
\text { or lower }\end{array}$ & 226 (79.3\%) & $93(85.3 \%)$ & $133(75.6 \%)$ & \multirow{5}{*}{0.124} \\
\hline Diploma & 15 (5.3\%) & $4(3.7 \%)$ & $11(6.3 \%)$ & \\
\hline Bachelor & 44 (15.4\%) & $12(11.0 \%)$ & $32(18.2 \%)$ & \\
\hline Master & $0(0 \%)$ & \multirow{2}{*}{ No valid cases } & & \\
\hline Doctorate & $0(0 \%)$ & & & \\
\hline Marital status & & & & \\
\hline Married & $192(67.4 \%)$ & 75 (68.8\%) & $117(66.5 \%)$ & \multirow{4}{*}{0.000} \\
\hline Divorced & $5(1.8 \%)$ & $2(1.8 \%)$ & $3(1.7 \%)$ & \\
\hline Widower & $41(14.4 \%)$ & $26(23.9 \%)$ & $15(8.5 \%)$ & \\
\hline Single & $47(16.5 \%)$ & $6(5.5 \%)$ & $41(23.3 \%)$ & \\
\hline \multicolumn{5}{|l|}{ Smoking status } \\
\hline Not a smoker & $222(77.9 \%)$ & $82(75.2 \%)$ & 140 (79.5\%) & \multirow{3}{*}{0.005} \\
\hline Former smoker & $28(9.8 \%)$ & $18(16.5 \%)$ & $10(5.7 \%)$ & \\
\hline Currently smoking & 35 (12.3\%) & $9(8.3 \%)$ & $26(14.8 \%)$ & \\
\hline \multicolumn{5}{|l|}{ Doing regular exercise } \\
\hline No & 165 (57.9\%) & 65 (59.6\%) & 100 (56.8\%) & \multirow{2}{*}{0.640} \\
\hline Yes & $120(42.1 \%)$ & 44 (40.4\%) & 76 (43.2\%) & \\
\hline \multicolumn{5}{|l|}{ Type of DM } \\
\hline DM type 1 & $117(41.1 \%)$ & 42 (38.5\%) & 75 (42.6\%) & \multirow{3}{*}{0.496} \\
\hline DM type 2 & 168 (58.9\%) & $67(61.5 \%)$ & $101(57.4 \%)$ & \\
\hline HbA1c, mean (SD) & $10.56(1.36)$ & & & \\
\hline \multicolumn{5}{|l|}{ Duration of having DM } \\
\hline Less than 1 year & 10 (3.5\%) & $3(2.8 \%)$ & $7(4.0 \%)$ & \\
\hline $6-10$ years & 41 (14.4\%) & 10 (9.2\%) & 31 (17.6\%) & 11 \\
\hline
\end{tabular}




\section{Cureus}

More than 10 years

Mode of current treatment

Oral medications

$80(28.1 \%)$

205 (71.9\%)

Insulin injections
96 (88.1\%)

35 (32.1\%)

74 (67.9\%)
$138(78.4 \%)$

$45(25.6 \%)$

$131(74.4 \%)$

TABLE 1: Demographic characteristics of the study sample $(n=285)$.

All variables were tested using Fisher's exact test.

DM, diabetes mellitus; SD, standard deviation

The mean shoulder pain intensity for all patients was $2.22(\mathrm{SD}=3.45)$, ranging from 1.65 ( $\mathrm{SD}=2.90)$ to 2.60 $(\mathrm{SD}=3.71)$, according to different age groups, and showed a significant correlation $(\mathrm{p}<0.05)$. And across gender, it was $1.46(\mathrm{SD}=2.61)$ in males $2.85(\mathrm{SD}=3.91)$ in females $(\mathrm{p}<0.001)$. Regarding different smoking status, the intensity of the pain ranged from $1.20(\mathrm{SD}=2.31)$ to $3.04(\mathrm{SD}=2.98)$, and regarding different durations of $\mathrm{DM}$, it ranged from $1.20(\mathrm{SD}=1.98)$ to $2.39(\mathrm{SD}=3.52)$. The intensity was $1.93(\mathrm{SD}=3.25)$ in type I DM and $2.42(\mathrm{SD}=3.58)$ in type II DM (Table 2). 


\section{Cureus}

\section{Variable}

All participants

Age, years

0-17

$18-44$

45-64

$65-96$

$p$-Value

Gender

Male

Female

p-Value

Smoking status

Not a smoker

Former smoker

Currently smoking

$p$-Value

\section{Duration of DM}

Less than 1 year

6-10 years

More than 10 years

$p$-Value

Type of DM

DM type 1

DM type 2

p-Value
2.42 (3.58)

Mean shoulder pain intensity (SD)

$2.22(3.45)$

$1.65(2.90)$

$1.13(2.25)$

$2.60(3.71)$

$2.58(3.75)$

0.023

$1.46(2.61)$

$2.85(3.91)$

0.001

2.28 (3.62)

$3.04(2.98)$

$1.20(2.31)$

0.224

$1.20(1.98)$

$1.51(3.21)$

2.39 (3.52)

0.104

0.238

\section{TABLE 2: Mean (SD) of shoulder pain intensity in demographic variables.}

DM, diabetes mellitus; SD, standard deviation

Table 3 demonstrates the participants' answers to different shoulder pain-related problems. Regarding throwing a ball overhand, $10.1 \%$ of the patients could not do it, $36.7 \%$ had no problem doing it, and $26.6 \%$ had slight-to-moderate trouble in throwing a ball overhand. Also, 20.2\% of the patients could not sleep over their shoulder, whereas $29.4 \%$ had no problem; $4.6 \%$ could not put on their coat without assistance, whereas $67.9 \%$ could. In addition, $4.6 \%$ of patients could not wash their back, whereas $63.3 \%$ had no difficulties in doing it. Regarding using toilet tissue, a very small percent (1.8\%) could not use them without assistance, whereas $70.6 \%$ could. Also, $4.6 \%$ of the cases had no ability to comb or wash their hair, whereas $69.7 \%$ had no problem in doing it. In terms of weight lifting, $45.9 \%$ of the patients could not lift $10 \mathrm{~kg}$ above the level of their shoulder, whereas $17.4 \%$ could; $17.4 \%$ of the patients could not reach a shelf over their head, whereas $44 \%$ could. Due to shoulder pain and movement restriction, $25.7 \%$ of the cases could not perform their regular activities or do their full-time work, whereas $39.4 \%$ had no problem in doing their work or daily activities. Moreover, 29.4\% could not play regular sports, whereas $34.9 \%$ could. 


\section{Cureus}

\begin{tabular}{|c|c|c|c|c|}
\hline Variable & No, n (\%) & $\begin{array}{l}\text { Moderate trouble, } n \\
(\%)\end{array}$ & $\begin{array}{l}\text { Slight trouble, } n \\
(\%)\end{array}$ & $\begin{array}{l}\text { Yes, n } \\
(\%)\end{array}$ \\
\hline Can you throw a ball overhand? & $\begin{array}{l}11 \\
(10.1 \%)\end{array}$ & $29(26.6 \%)$ & $29(26.6 \%)$ & $\begin{array}{l}40 \\
(36.7 \%)\end{array}$ \\
\hline Can you sleep on your shoulder comfortably? & $\begin{array}{l}22 \\
(20.2 \%)\end{array}$ & $31(28.4 \%)$ & $24(22 \%)$ & $\begin{array}{l}32 \\
(29.4 \%)\end{array}$ \\
\hline Can you put on your coat unassisted? & $5(4.6 \%)$ & $13(11.9 \%)$ & $17(15.6 \%)$ & $\begin{array}{l}74 \\
(67.9 \%)\end{array}$ \\
\hline Can you wash your back? & $5(4.6 \%)$ & $20(18.3 \%)$ & $15(13.8 \%)$ & $\begin{array}{l}69 \\
(63.3 \%)\end{array}$ \\
\hline Can you use toilet tissue? & $2(1.8 \%)$ & $14(12.8 \%)$ & $16(14.7 \%)$ & $(70.6 \%)$ \\
\hline Can you comb/wash your hair? & $5(4.6 \%)$ & $15(13.8 \%)$ & $13(11.9 \%)$ & $\begin{array}{l}76 \\
(69.7 \%)\end{array}$ \\
\hline Can you lift $10 \mathrm{~kg}$ above the level of your shoulder? & $\begin{array}{l}50 \\
(45.9 \%)\end{array}$ & $28(25.7 \%)$ & $12(11 \%)$ & $\begin{array}{l}19 \\
(17.4 \%)\end{array}$ \\
\hline Can you reach a shelf over your head? & $\begin{array}{l}19 \\
(17.4 \%)\end{array}$ & $24(22 \%)$ & $18(16.5 \%)$ & $48(44 \%)$ \\
\hline $\begin{array}{l}\text { Does your shoulder allow you to work full time or perform regular } \\
\text { activities? }\end{array}$ & $\begin{array}{l}28 \\
(25.7 \%)\end{array}$ & $19(17.4 \%)$ & $19(17.4 \%)$ & $\begin{array}{l}43 \\
(39.4 \%)\end{array}$ \\
\hline Does your shoulder allow you to do your regular sports? & $\begin{array}{l}32 \\
(29.4 \%)\end{array}$ & $23(21.1 \%)$ & $18(14.7 \%)$ & $\begin{array}{l}38 \\
(34.9 \%)\end{array}$ \\
\hline
\end{tabular}

TABLE 3: Answers to shoulder pain.

The mean shoulder ASES score for all patients was 82.18 ( $\mathrm{SD}=27.20)$, ranging from 77.82 (SD=31.08) to 92 ( $\mathrm{SD}=16.55)$, according to different age groups, with 87.88 ( $\mathrm{SD}=21.71$ ) in males and 77.46 (30.28) in females $(\mathrm{p}<0.001)$. It ranged from 75.83 (23.58) to 89.66 ( $\mathrm{SD}=19.39)$ with different smoking status and from 80.54 $(\mathrm{SD}=28.12)$ to $90.66(\mathrm{SD}=15.53)$ in different durations of $\mathrm{DM}$, with $83.93(\mathrm{SD}=25.87)$ in type I DM and 80.96 $(\mathrm{SD}=28.09)$ in type II DM. The mean shoulder ASES score for all patients showed significant association with age, gender, and duration of $\mathrm{DM}(\mathrm{p}<0.05)$, whereas other demographic variables did not show any association ( $\mathrm{p}>0.05)$ (Table 4). 


\section{Cureus}

\section{Variable}

All participants

Age, years

0-17

18-44

45-64

$65-96$

$p$-Value

Gender

Male

Female

p-Value

Smoking status

Not a smoker

Former smoker

Currently smoking

$p$-Value

Duration of DM

Less than 1 year

6-10 years

more than 10 years

p-Value

Type of DM

DM type 1

DM type 2

p-Value
Mean of ASES score (SD)

82.18 (27.20)

$86.0(23.82)$

$92.0(16.55)$

79.38 (28.62)

77.82 (31.08)

0.008

87.88 (21.71)

$77.46(30.28)$

0.001

$81.80(28.47)$

$75.83(23.58)$

89.66 (19.39)

0.273

$90.66(15.53)$

89.43 (22.48)

80.54 (28.12)

0.057

$83.93(25.87)$

80.96 (28.09)

0.366

TABLE 4: Mean (SD) ASES score in demographic variables.

ASES, American Shoulder and Elbow Surgeons; DM, diabetes mellitus; SD, standard deviation

\section{Discussion}

Musculoskeletal disease is one of the most common complications in DM patients. The global prevalence of DM among adults (over 18 years of age) has risen from 4.7\% in 1980 to 9.5\% in 2018 [15]. The shoulder or glenohumeral joint is a triaxial joint that connects the head of the humerus with the glenoid fossa of the scapula. This joint has greater mobility than any other joint in the body [16]. Among the various musculoskeletal diseases, shoulder pain is one of the most common complaints among DM patients. In general, it is characterized by pain and limited range of motion of one or both shoulders. Shoulder pain not only causes a decreased quality of life but also leads to disability in daily activities, and might interfere directly or indirectly with control of metabolic processes [17]. The exact mechanism that leads to the occurrence of shoulder pain in diabetic patients has not been recognized. The two conditions [7] that have similar mechanisms as of DM are (i) impairment of microcirculation and (ii) process of non-enzymatic glycosylation. It has been observed that hyperglycemia causes the development of non-enzymatic glycosylation products and leads to the formation of advanced glycosylation end-products (AGEs). AGEs escalate cross-linking in tendons, collagen, and ligaments, making them weaker and stiffer. They also relate with their receptors present on tenocytes and fibroblasts, thus causing inflammatory changes [18]. 
Moreover, the unfavorable microvascular situation created by hyperglycemia occurs around the shoulder joint as well. The impaired circulation causes overproduction of free radicals and tissue hypoxia causing potential apoptosis. This destruction causes damage to tissues of the joint and leads to various degenerative changes. The cross-linking collagen gathered in the shoulder capsule causes joint stiffness. Hyperglycemia leads to the chronic inflammatory process that increases the inflammation reaction in the synovium. All these factors lead to capsular fibrosis of the shoulder joint [19]. In Saudi Arabia, the prevalence and patterns of chronic pain due to musculoskeletal system among rheumatology patients were observed to be $42 \%$. The most common sites were low back pain, neck pain, and shoulder pain, with a frequency of $52 \%, 41 \%$, and $26 \%$, respectively [20].

In this study, $38.2 \%$ of the diabetic patients suffered from shoulder pain, with $71 \%$ of them being females, especially in the age group of 45-64 years, whereas according to past studies [21-22], the shoulder pain prevalence in the general population was reported to be $2-5 \%$ only. Also, $68.8 \%$ of the married participants could be affected because of the increase in post-marriage stress levels compared to divorced, widower, or single.

Previously, studies have shown that the mode of anti-diabetic medications also affects the prevalence of shoulder pain. Non-insulin-dependent patients (type II) were 1.59 times more affected with shoulder pain than type I, and the results were comparable to past studies [23-24].

Cagliero et al. [19] found higher levels of HbA1c in diabetic patients with shoulder soft tissue musculoskeletal complaints. Arkkila et al. [11] also found that type 2 DM patients with inadequate glycemic control (HbA1c greater than 9\%) had more shoulder capsulitis. Similar results were noted in our study, where the $\mathrm{HbA1c}$ levels were found to be $10.56 \pm 1.36$, but no significant correlation between HbA1c and shoulder pain was found.

Wong et al. [25] found that chronic illness, increasing age, marital discord, the presence of anxiety and depression, lack of exercise, and poor quality of life were found to be significantly associated with the presence of DM-associated shoulder pain. Similar results were noted in our study as $65 \%$ of patients were not doing regular exercise, and most of the patients were having a strenuous lifestyle because of the pressure of education. In our study, no association was found between smoking habit and prevalence $(\mathrm{p}=0.05)$ of shoulder pain in the patients. Regarding the overall effect of shoulder pain over the quality of daily life, it was noted that only $36.7 \%$ of patients did not have any trouble in throwing the ball overhand. In addition, $29.4 \%$ of the patients replied that they could sleep on their affected shoulder comfortably, and $67.9 \% \%$ of the patients could wear their coat unassisted. When asked about washing back while bathing and using toilet tissue paper, $63.3 \%$ and $70.6 \%$ of patients, respectively, replied positively to it. Also, $69.7 \%$ of the patients with DM-associated shoulder problem replied that they could do their hairwashing and comb independently, and $45.9 \%$ of patients totally refused to lift $10 \mathrm{~kg}$ of weight above their shoulder because of unbearable shoulder pain and decreased mobility of their affected shoulder during this activity. Only $44 \%$ of the patients were able to reach a shelf above their heads easily. The majority (60.6\%) of patients felt unconformable to work full time or perform regular activities with DM-associated shoulder pain, and $65.1 \%$ of patients responded that they could do their regular sports activities. All these responses showed that chronic shoulder pain put a substantial risk on health outcomes such as physical activity and dietary habits, and these lifestyle changes may, in turn, aggravate type $2 \mathrm{DM}$ in these patients. The results were in agreement with many past studies [26].

The main limitation of the study is that due to the small sample size, no significant association between the results and the duration of DM was found. Moreover, it can be argued that the questions on smoking could be subjected to reporting bias. Due to its cross-sectional design, this study does not allow an analysis of prior glycemic control in the occurrence of pain and shoulder dysfunction.

We encourage that future interventional trials or prospective cohort studies be conducted in order to verify the causality for the outcomes of this study, which could help in the development of new strategies to minimize the suffering of diabetic individuals and promote a good quality of life. This study is recent and addresses the current gap in the contemporary literature.

\section{Conclusions}

A high prevalence of shoulder dysfunction in diabetic individuals will urge clinical practitioners to examine and identify musculoskeletal findings in diabetic patients. Early diagnosis and treatment of DM can reduce the development of shoulder pain that can cause impairment in the routine functioning of diabetic patients. Early identification of signs of musculoskeletal complications can prove to be a valuable finding in the comprehensive care of diabetic patients. The increasing prevalence of shoulder dysfunction is making physicians alert regarding early diagnosis and management of the disease. Thus, it should be mandatory to include screening, prevention, and rehabilitation strategies for shoulder dysfunction in diabetic care programs to improve the daily lifestyle of the patients.

\section{Additional Information}




\section{Disclosures}

Human subjects: Consent was obtained by all participants in this study. Ethical Committee of the Security Forces Hospital issued approval H-01-R-069. Animal subjects: All authors have confirmed that this study did not involve animal subjects or tissue. Conflicts of interest: In compliance with the ICMJE uniform disclosure form, all authors declare the following: Payment/services info: All authors have declared that no financial support was received from any organization for the submitted work. Financial relationships: All authors have declared that they have no financial relationships at present or within the previous three years with any organizations that might have an interest in the submitted work. Other relationships: All authors have declared that there are no other relationships or activities that could appear to have influenced the submitted work.

\section{Acknowledgements}

The authors would like to thank the participants in this study for their patience during the interview. The authors also acknowledge the support of the Security Forces Hospital for facilitating the data collection and the conduction of the telephone interviews.

\section{References}

1. Lebiedz-Odrobina D, Kay J: Rheumatic manifestations of diabetes mellitus. Rheum Dis Clin North Am. 2010, 36:681-99. 10.1016/j.rdc.2010.09.008

2. Arkkila PE, Gautier JF: Musculoskeletal disorders in diabetes mellitus: an update . Best Pract Res Clin Rheumatol. 2003, 17:945-70. 10.1016/j.berh.2003.11.001

3. Garcilazo C, Cavallasca JA, Musuruana JL: Shoulder manifestations of diabetes mellitus. Curr Diabetes Rev. 2010, 6:334-40. 10.2174/157339910793360824

4. Lindgren I, Gard G, Brogårdh C: Shoulder pain after stroke - experiences, consequences in daily life and effects of interventions: a qualitative study. Disabil Rehabil. 2018, 40:1176-182. 10.1080/09638288.2017.1290699

5. Manninen P, Riihimäki H, Heliövaara M, Mäkelä P: Overweight, gender and knee osteoarthritis. Int J Obes Relat Metab Disord. 1996, 20:595-7.

6. Alqurashi KA, Aljabri KS, Bokhari SA: Prevalence of diabetes mellitus in a Saudi community . Ann Saudi Med. 2011, 31:19-23. 10.4103/0256-4947.75773

7. Thomas SJ, McDougall C, Brown ID, et al.: Prevalence of symptoms and signs of shoulder problems in people with diabetes mellitus. J Shoulder Elbow Surg. 2007, 16:748-51. 10.1016/j.jse.2007.02.133

8. Cho CH, Song KS, Kim BS, Kim DH, Lho YM: Biological aspect of pathophysiology for frozen shoulder . Biomed Res Int. 2018, 2018:7274517. 10.1155/2018/7274517

9. Wyatt LH, Ferrance RJ: The musculoskeletal effects of diabetes mellitus . J Can Chiropr Assoc. 2006, 50:4350. https://www.ncbi.nlm.nih.gov/pmc/articles/PMC1839979/

10. Laslett LL, Burnet SP, Redmond CL, McNeil JD: Predictors of shoulder pain and shoulder disability after one year in diabetic outpatients. Rheumatology (Oxford). 2008, 47:1583-6. 10.1093/rheumatology/ken333

11. Arkkila PE, Kantola IM, Viikari JS, Ronnemaa T: Shoulder capsulitis in type I and II diabetic patients: association with diabetic complications and related diseases. Ann Rheum Dis. 1996:907-14. 10.1136/ard.55.12.907

12. Abate M, Schiavone C, Salini V, Andia I: Management of limited joint mobility in diabetic patients . Diabetes Metab Syndr Obes. 2013, 6:197-207. 10.2147/dmso.s33943

13. El-Metwally A, Shaikh Q, Aldiab A, et al.: The prevalence of chronic pain and its associated factors among Saudi Al-Kharj population; a cross sectional study. BMC Musculoskelet Disord. 2019, 25:177. 10.1186/s12891-019-2555-7

14. Aldossari KK, Aldiab A, Al-Zahrani JM, et al.: Prevalence of prediabetes, diabetes, and its associated risk factors among males in Saudi Arabia: a population-based survey. J Diabetes Res. 2018, 2018:2194604. https://doi.org/10.1155/2018/2194604

15. Sarwar N, Gao P, Seshasai SR, et al.: Diabetes mellitus, fasting blood glucose concentration, and risk of vascular disease: a collaborative meta-analysis of 102 prospective studies. Lancet. 2010, 26:2215-22. 10.1016/s0140-6736(10)60484-9

16. Kisner C, Colby LA, Borstad J: The shoulder and shoulder girdle. Therapeutic Exercise: Foundations and Techniques. Kisner JBC, Colby LA (ed): F.A. Davis, Philadelphia, PA; 2018. 546-622.

17. Lan Hsu C, Sheu WHH: Diabetes and shoulder disorders. J Diabetes Investig. 2016, 7:649-50. 10.111//jdi.12491

18. Goldin A, Beckman JA, Schmidt AM, Creager MA: Advanced glycation end products: sparking the development of diabetic vascular injury. Circulation. 2006, 114:597-605. 10.1161/CIRCULATIONAHA.106.621854

19. Cagliero E, Apruzzese W, Perlmutter G, Nathan DM: Musculoskeletal disorders of the hand and shoulder in patients with diabetes mellitus. Am J Med. 2002, 112:487-90. 10.1016/s0002-9343(02)01045-8

20. Moussa S, Al Zaylai F, Alomar A, Al Oufi H, AL Nodali N, Alshmmry RTA, Al-Enzy S: Musculoskeletal pain in hail community: medical and epidemiology study; Saudi Arabia. Int J Sci Res. 2015, 4:1292-99. 10.21275/v4i11.nov151365

21. Moren-Hybbinette I, Moritz U, Schersten B: The clinical picture of the painful diabetic shoulder--natural history, social consequences, and analysis of concomitant hand syndrome. Acta Med Scand. 1987:73-82. https://doi.org/10.1111/j.0954-6820.1987.tb01247.x

22. Lequesne M, Dang N, Bensasson M, Mery C: Increased association of diabetes mellitus with capsulitis of the shoulder and shoulder-hand syndrome. Scand J Rheumatol. 1977, 6:53-6.

23. Zreik NH, Malik RA, Charalambous CP: Adhesive capsulitis of the shoulder and diabetes: a meta-analysis of 


\section{Cureus}

prevalence. Muscles Ligaments Tendons J. 2016, 6:26-34. 10.11138/mltj/2016.6.1.026

24. Yian EH, Contreras R, Sodl JF: Effects of glycemic control on prevalence of diabetic frozen shoulder . J Bone Joint Surg Am. 2012, 94:919-23. 10.2106/JBJS.J.01930

25. Wong WS, Fielding R: Prevalence and characteristics of chronic pain in the general population of Hong Kong. J Pain. 2011, 12:236-45. 10.1016/j.jpain.2010.07.004

26. Lin TT, Lin CH, Chang CL, Chi CH, Chang ST, Sheu WH: The effect of diabetes, hyperlipidemia, and statins on the development of rotator cuff disease: a nationwide, 11-year, longitudinal, population-based followup study. Am J Sports Med. 2015, 43:2126-32. https://doi.org/10.1177/0363546515588173 